\title{
Disposition Index (DI) is not Improved with High-Intensity Intermittent Exercise in Adults with Hyperinsulinemia and Pre-Diabetes
}

\author{
Oana Ancu', Jane Naufahu ${ }^{2}$, Richie Barclay ${ }^{1}$, Peter Watt ${ }^{3}$ and Richard WA Mackenzie ${ }^{1 *}$ \\ ${ }^{1}$ Department of Life Sciences, University of Roehampton, London, UK \\ ${ }^{2} S$ Shool of Life Sciences, University of Westminster, London, UK \\ ${ }^{3}$ Centre for Sport and Exercise Science and Medicine (SESAME), University of Brighton, UK
}

\begin{abstract}
The progression from pre-diabetes to overt type 2 diabetes is largely attributed to $\beta$-cell dysfunction and reduced insulin responsiveness. Exercise improves $\beta$-cell function in type 2 diabetics, however in pre-diabetic populations there is no data to support a similar response to acute high intensity exercise. Nine individuals diagnosed with prediabetes [HbA1c; $6.1(0.2) \%)]$ underwent a resting control, a continuous exercise and a high-intensity exercise trial. A labeled $\left(\left[6,6^{2} \mathrm{H}_{2}\right] \mathrm{glu}-\right.$ cose) intravenous glucose tolerance test (IVGTT) was administered immediately after each trial to calculate $\beta$-cell function, $1^{\text {st }}$ [acute $\left(A I R_{g}\right)$ ] and $2^{\text {nd }}$ phase insulin response to intravenous glucose and disposition index $(\mathrm{DI})$. Data modelling indicated $\operatorname{AIR}_{g}(P=0.68)$ and $2^{\text {nd }}$ phase insulin responsiveness $(P=0.294)$ were not different between trials. Additionally, insulin response in relation to insulin action (DI) was not statistically different between trials $(P=0.394)$. In conclusion, acute high intensity exercise does not improve $\mathrm{DI}$ and $\beta$-cell function in individuals with prediabetes.
\end{abstract}

\section{Keywords}

Insulin resistance, Pre-diabetes, $\beta$-cell function, Disposition index

\begin{abstract}
Abbreviations
HIIE: High intensity intermittent exercise; IVGTT: Intravenous glucose tolerance test; DI: Disposition index; T2D: Type 2 diabetes; GSIS: Glucose-stimulated insulin secretion; AIR: Acute insulin response to glucose; LT: Lactate Threshold; HOMAIR: Homeostasis model of insulin resistance; $\mathrm{S}_{1}^{2^{*}}$ : Insulin sensitivity; $\mathrm{MBCl}$ : Modified beta cell index; $\mathrm{HOMA}_{\beta-\text { cell }}$ : HOMA of $\beta$-cell function; G-6-P: Glucose-6-phosphate; ATP: Adenosine triphosphate; GLUT-2: Glucose transporter type 2; Akt: Protein kinase B; AS160: Akt substrate of $160 \mathrm{kDa}$
\end{abstract}

\section{Introduction}

Type 2 diabetes (T2D) is a complex metabolic disease characterized by defects in $\beta$-cell function, glucose effectiveness, insulin resistance and hepatic glucose $[1,2]$. Insulin resistance, a characteristic of pre-diabetes, is widely accepted as the starting point for the progression from glucose intolerance to overt type 2 diabetes. Thus, a great deal of research has been directed towards understanding insulin resistance in skeletal muscle. Research has consistently shown that defects in insulin signaling and insulin-mediated glucose uptake in skeletal muscle contribute to whole body hyperglycemia [3-10]. We have recently shown that high intensity intermittent exercise (HIIE) reverses insulin resistance in pre-diabetic individuals which was partly due to an increase in Akt-AS160 signaling in skeletal muscle [11]. In this data set, we measured $\beta$-cell function in the same population following HIIE and continuous exercise to assess if improvements in whole body glu- cose control can also be attributed to insulin secretion and action [i.e. disposition index (DI)].

The ability of muscle contraction to improve glycaemic control via increased insulin and non-insulin-mediated pathways in skeletal muscle is well established [12-16]. In addition, exercise is known to improve muscle blood flow and

*Corresponding author: Richard W.A. Mackenzie, PhD, Department of Life Sciences, University of Roehampton, Whitelands College, London, SW15 4DJ, UK, Tel: +44-208392-3562

Accepted: February 04, 2021

Published online: February 06, 2021

Citation: Ancu O, Naufahu J, Barclay R, et al. (2021) Disposition Index (DI) is not Improved with High-Intensity Intermittent Exercise in Adults with Hyperinsulinemia and Pre-Diabetes. Clin Diabetes Res 5(1):55-61 
Citation: Ancu O, Naufahu J, Barclay R, et al. (2021) Disposition Index (DI) is not Improved with High-Intensity Intermittent Exercise in Adults with Hyperinsulinemia and Pre-Diabetes. Clin Diabetes Res 5(1):55-61

therefore substrate flux [16-19], reduce lipid mediated insulin resistance [20] and hepatic glucose dysregulation [11]. These exercise-induced changes in insulin action and glucose flux likely explain most of the benefits of exercise in those with, and at risk of type 2 diabetes $[6,9,21]$. Thus, it is clear that exercise offers improvements in peripheral insulin action and cardio-metabolic health. Yet there are very few studies that have assessed the effects of exercise intensity on $\beta$-cell function. The limited work available suggests that exercise can improve $\beta$-cell function in type 2 diabetics due to a reduction in pancreatic glucose exposure rather than improvements in $\beta$-cell function itself [22]. For example, two weeks of exercise training improved glucose-stimulated insulin secretion (GSIS) in individuals with prediabetes, in response to an oral glucose challenge [23]. While comprehensive, one of the limitations of the prior work was the use of an oral glucose tolerance test (OGTT) to assess glucose control. The current work employed the powerful two-compartment intravenous glucose tolerance test (IVGTT) to assess $\beta$-cell function relative to insulin action (i.e. DI). This is an important difference between Malin, et al. 2018 [23] and the current study, given that the reproducible pattern of insulin secretion in response to the IVGTT is less variable than the OGTT approach $[24,25]$. Indeed, measurement of insulin secretion with the OGTT is affected by gastric emptying, glucose absorption and the integrin effect.

Insulin resistance and insulin secretion are subject to a hyperbolic relationship with decreased insulin action being compensated with an increase in insulin release [13]. This relationship, represented by the DI, can be modelled using the parameters of insulin sensitivity and acute insulin response to glucose $\left(A I R_{g}\right)$, and is a physiological representation of the $\beta$-cells' compensatory response to changes in insulin sensitivity [26]. Acute HIIE is known to increase glucose disposal and insulin action to a greater extent than more moderate intensity bouts of exercise [11,13]. HIIE would arguably decrease insulin requirements beyond the acute period, likely due to improved insulin sensitivity [27] driven by a greater degree of glycogen depletion in both liver and skeletal muscle.

The purpose of the current research was to investigate pancreatic insulin responsiveness and $\mathrm{DI}$ in the acute period following both high intensity intermittent and continuous moderate intensity exercise in hyperinsulinemic pre-diabetic individuals using a labelled IVGTT.

\section{Methods}

\section{Participants and ethics}

Nine individuals with prediabetes ( 7 males and 2 females; $47 \pm 3$ years) were recruited for this study as described in [11]. The sample size was established using power calculation (powered to $0.95 \&$ alpha $=5 \%$ ) using estimated changes in measures of glucose control ( $\mathrm{S}_{1}{ }^{*}$ and $\beta$-cell function) from our previously published data [28]. Subjects' clinical characteristics (BMI, $32.0 \pm 2.4 \mathrm{~kg} / \mathrm{m}^{2}$; Body fat, $39 \pm 4.4 \%$; $\mathrm{L} ; \mathrm{HbA}_{1 \mathrm{c}^{\prime}}$ $6.10 .2 \%$; Fasting glucose, $5.3 \pm 0.7 \mathrm{mmol} / \mathrm{HOMA}_{\mathrm{IR}}, 3.3 \pm 0.8$; $\mathrm{HOMA}_{\beta \text {-Cell' }} 207 \pm 33$; Fasting insulin, $11.6 \pm 5.9 \mathrm{mmol} / \mathrm{L}$ ) are presented in Supplementary Table. Each participant was informed of the purpose, experimental procedures and any potential risks of the investigation prior to providing written consent to participate. Ethical approval for this study was granted by the local University Ethics Committee (Ref: 11_12_23) and conformed to standards set by the Declaration of Helsinki for human participants in research, except for a registration in a database. Glycated haemoglobin $\left(\mathrm{HbA}_{1 \mathrm{c}}\right)$ values of $>5.7 \%$ and $<6.4 \%$ were used to define individuals in a pre-diabetic state [29].

\section{Experimental Protocol}

The participants visited the laboratory on 4 separate occasions, each separated by 7-14 days. The first visit obtained preliminary data including: Fasting blood glucose and plasma insulin concentrations, blood lipids, $\mathrm{HbA}_{1 c^{\prime}}$ blood pressure, body mass, waist-to-hip ratio and body composition using Bod Pod (Life Measurement, Inc., Concord, CA, USA), as previously described [30]. A venous sample was drawn to measure $\mathrm{HbA}_{1 \mathrm{c}}$, fasting blood glucose and plasma insulin ( 2 $\mathrm{mL}$ EDTA blood). On the same preliminary visit, participants performed a lactate threshold (LT) test on a cycle ergometer (Lode Corival), using the same methodology previously described by [13]. Data obtained during the LT assessment was used to determine the exercise intensity for the subsequent continuous exercise trial at $90 \%$ of LT. Fasting blood glucose and plasma insulin levels were used to determine the homeostasis model of insulin resistance $\left[\mathrm{HOMA}_{\mathrm{IR}}\right.$; fasting insulin $(\mu \mathrm{U} / \mathrm{mL}) \times$ fasting glucose $(\mathrm{mmol} / \mathrm{L}) / 22.5]$ and $\mathrm{HOMA}$ of $\beta$-cell function $\left[\mathrm{HOMA}_{\beta-\text { Cell }} ; 20 \times\right.$ fasting insulin $(\mu \mathrm{U} / \mathrm{mL}) /$ fasting glucose -3.5 (mmol/L)].

On experimental days, volunteers attended the laboratory at approximate 8:30 am after a $12 \mathrm{hr}$ overnight fast, abstained from caffeine and alcohol for $24 \mathrm{hr}$ and exhaustive exercise for $72 \mathrm{hr}$. An 18-gauge cannula was positioned into a dorsal hand vein to allow for frequent sampling of arterialised blood, using a thermoregulated hot box $\left(\sim 60^{\circ} \mathrm{C}\right)$. A second 18-gauge cannula was placed into a prominent contralateral antecubital vein for administration of intravenous glucose. In a randomised fashion, each participant completed a resting control trial (Rest; sitting), a continuous exercise trial at an intensity equal to 90\% LT (Continuous) (cycle ergometer, Lode Corival) and a HIIE (6 $\times 30 \mathrm{sec}$ Wingate test) (Intermittent) (Monarch $894 \mathrm{E}$, Weight Ergometer). Each $30 \mathrm{sec}$ sprint was separated by $9.5 \mathrm{~min}$ of passive recovery in the intermittent trial. All trials lasted $60 \mathrm{~min}$. A sterile glucose solution comprising labelled $\left(28.4 \mathrm{mg} / \mathrm{kg}\left[6,6^{2} \mathrm{H}_{2}\right]\right.$ glucose $)$ glucose and 250 $\mathrm{mg} / \mathrm{kg}$ of unlabeled glucose was administered via the antecubital cannula. Blood samples were drawn over the ensuing 240 minutes as previously described [13] (labeled IVGTT). Blood glucose concentrations were measured immediately in triplicate using a YSI 2300 (STAT; Yellow Springs, USA). The remaining samples were centrifuged $\left(4^{\circ} \mathrm{C}, 10 \mathrm{~min}, 5000 \mathrm{rpm}\right)$, plasma was then immediately stored at $-80^{\circ} \mathrm{C}$ for subsequent analyses of plasma insulin, endogenous glucose and isotope enriched $\left[6,6^{2} \mathrm{H}_{2}\right]$ glucose concentrations.

\section{Blood Analysis}

Glucose enriched plasma samples were deproteinized in ethanol (99\%) with the resulting supernatants centrifuged to 
Citation: Ancu O, Naufahu J, Barclay R, et al. (2021) Disposition Index (DI) is not Improved with High-Intensity Intermittent Exercise in Adults with Hyperinsulinemia and Pre-Diabetes. Clin Diabetes Res 5(1):55-61

dryness. Hydroxylamine hydrochloride $(100 \mu \mathrm{l}, 0.18 \mathrm{M}$ pyridine) was then added before a $60 \mathrm{~min}$ incubation at $70^{\circ} \mathrm{C}$. After which, Bis(trimethyl)trifluoroacetamide: $1 \%$ trimethyl-chorosilane (TMCS; 99\%) (Sigma-Aldrich, Exeter, UK) was added before a further incubation $\left(45 \mathrm{~min}\right.$ at $\left.70^{\circ} \mathrm{C}\right)$. Samples were then analysed for glucose derivatives of 319 (unlabeled glucose; tracee) and $321\left(\left[6,6^{2} \mathrm{H}_{2}\right]\right.$ glucose; tracer) by GC/MS. Endogenous glucose concentrations were measured in whole blood (YSI 2300; STAT; Yellow Springs, USA) and plasma insulin using a commercially available ELISA (DRG diagnostics, UK). Intra-assay and inter-assay coefficient of variation for insulin enzyme-linked immunosorbent assay was $<3.8 \%$.

\section{Data Modelling}

Plasma insulin, endogenous glucose concentrations and labelled glucose values were used to model the following: Two compartment models of $S_{1}^{2^{*}}, A I R_{g}$ and $D I\left(D I=S_{1}{ }^{2 *} \times A I R\right)$, as described previously [26,31] (SAAMII Institute, Seattle, WA). Second phase insulin secretion ( $2^{\text {nd }}$ phase IS) was estimated as $\sum_{\text {I area }=12}^{240}$ I area ; I area ${ }_{12-240}$ denote insulin area values from $12-240 \mathrm{~min}$ and used to calculate $2^{\text {nd }}$ phase disposition index $\left(\mathrm{S}_{1}^{2^{*}} \times 2^{\text {nd }}\right.$ phase IS).

Peak insulin/fasting insulin $\left(I_{p} / I_{0}\right)$, and the area under the glucose curve of IVGTT ( $A \cup C_{\text {ins }}$ ) were calculated as previously described by [32], in order to asses first-phase insulin secretion. Modified beta cell index $(\mathrm{MBCl})$ was calculated as $\left(\mathrm{G}_{0}\right.$ $\left.\times I_{0}\right) /\left(G_{2}+G_{1}-2 G_{0}\right)$, where $G_{0}, G_{1}$ and $G_{2}$ denote blood glucose levels (mmol/L) at 0,1 and $2 \mathrm{~h}$, respectively, and $\mathrm{I}_{0}$ denote insulin levels $(\mu \mathrm{U} / \mathrm{mL})$ at $0 \mathrm{hr}$ [33].

\section{Statistical Analyses}

Differences over time and between the conditions tested were evaluated using one-way repeated measures ANOVA. All statistical tests were carried out using the statistical software SPSS (version 23). Data are expressed as mean (SEM). Statistical significance was accepted at $P<0.05$.

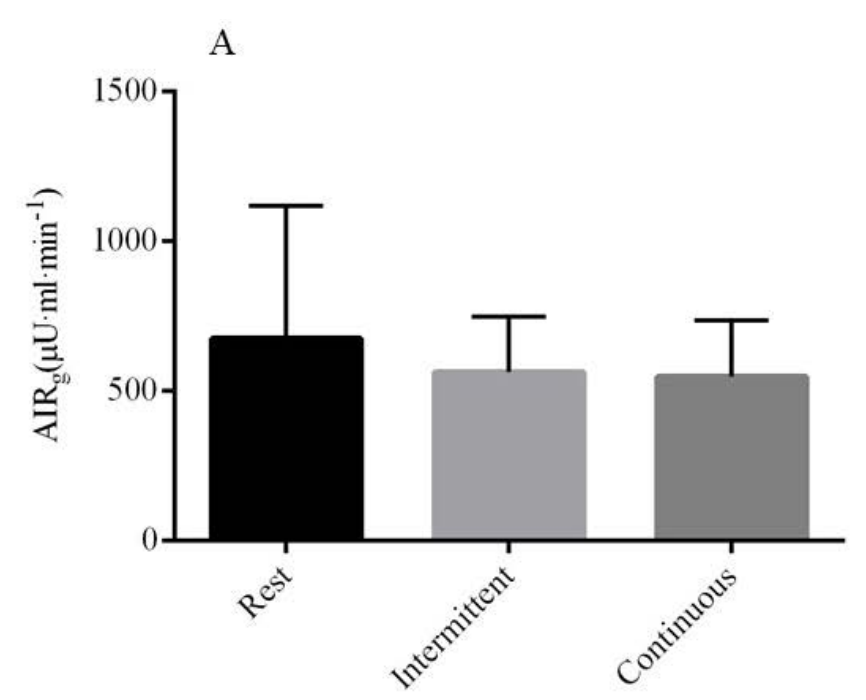

\section{Results}

AUC $_{\text {ins }}$ (data shown in Supplementary Figure) was not significantly lower when compared to the exercise trials $(P=$ 0.339). AIR was measured from 0 to 10 min post the IV glucose load $\left(A I R_{g}\right)$ and is shown in Figure 1. Again, both exercise bouts did not reduce the acute insulin response to IV glucose $(P=0.618)$. In an identical manner comparison for second phase insulin response during IVGTTs (12-240 $\mathrm{min}$ ) showed no difference between trials $(P=0.294)$.

$D I$ is a measure of the relationship between insulin sensitivity and acute insulin response to glucose $\left(D I=S_{1}{ }^{2 *} \times A I R_{g}\right)$ in the first phase $\left(\mathrm{DI}^{1 \text { st }} 0-10 \mathrm{~min}\right)$ post the intravenous glucose challenge and is therefore a key indicator of the $\beta$-cell responsiveness to an acute increase in blood glucose relative to whole body insulin sensitivity. Groupwise comparisons of DI between the trials also showed no difference $(P=0.394)$, as shown in Figure 2. To provide a clearer picture of the tight relationship between $\beta$-cell function and insulin sensitivity, DI was also calculated for the $2^{\text {nd }}$ phase insulin response to IV glucose ( $\left.D \mathrm{I}^{\text {2nd; }} 12-240 \mathrm{~min}\right)$ and there was no significant difference noted $(P=0.385)$.

Figure 3 shows both modified $\beta$-cell function index (MBCl) and ratio between peak insulin and fasting insulin $\left(I_{p} / I_{0}\right)$, which were calculated using the data obtained from the IVGTT following rest, intermittent and continuous exercise trials. Statistical analysis showed no difference between trials for $\mathrm{MBCl}$ $(P=0.239)$ or $\mathrm{I}_{\mathrm{p}} / \mathrm{I}_{0}(P=0.982)$.

\section{Discussion}

The primary aim of this study was to assess the effects of acute exercise on $\beta$-cell responsiveness and DI in men and women with prediabetes. Individuals with type 2 diabetes are able to improve DI after acute HIIE due to improved $\beta$-cell function [34], thus it was hypothesized that HIIE would improve DI in individuals with prediabetes, who share similar characteristics. In the current study, DI in the acute (0-10 min post IV glucose) and moderate time frame (10-240 $\mathrm{min}$ ) were

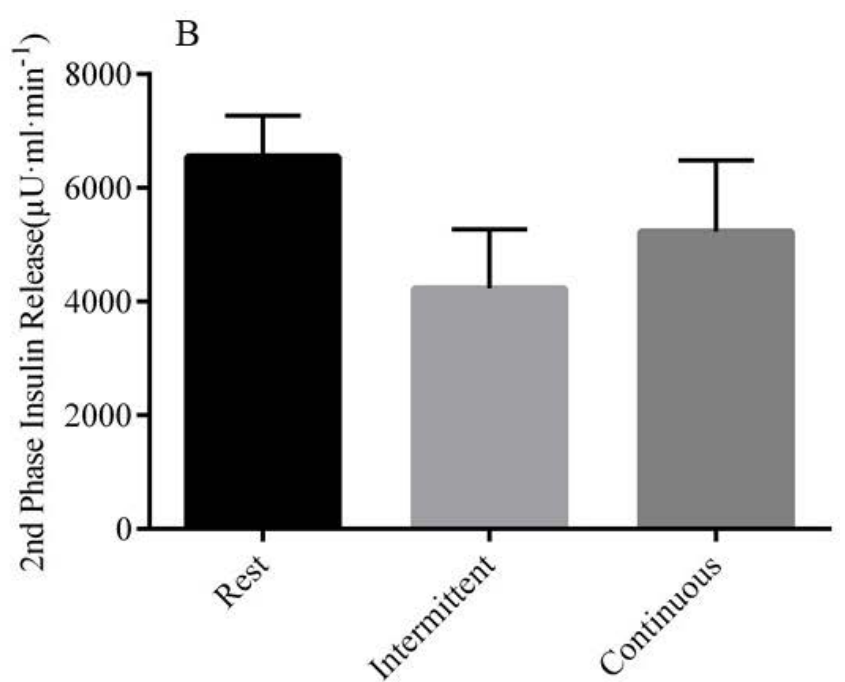

Figure 1: Shows AIRg (A) and $2^{\text {nd }}$ phase insulin response (B) to labelled glucose loads in the $4 \mathrm{hr}$ post rest, intermittent and continuous exercise trials. No significant difference was noted between exercise trials $(P<0.05)$. Data are expressed as mean \pm SEM. 

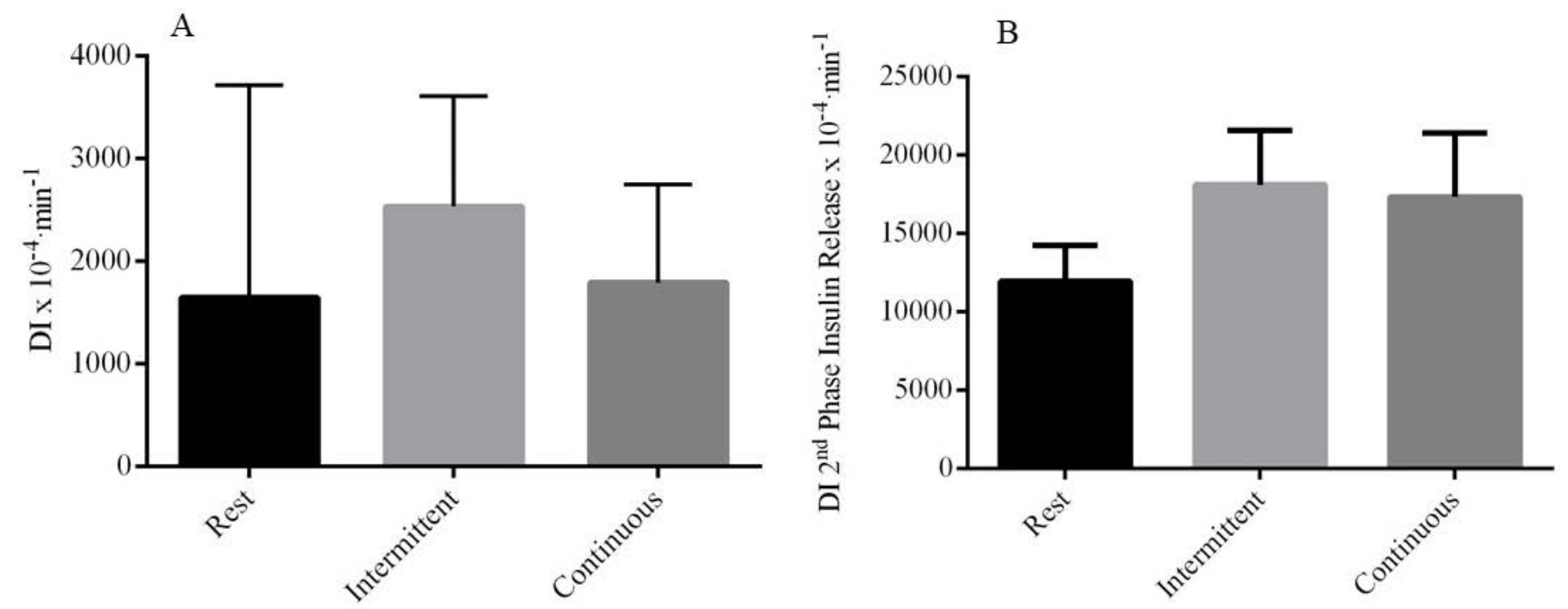

Figure 2: Disposition Index (DI) during IVGTT post rest, intermittent and continuous exercise trials for both the first phase (DI $\left.1^{\text {st }}\right)(A)$ and $2^{\text {nd }}$ phase insulin response $\left(\mathrm{DI} 2^{\text {nd }}\right)(B)$ to IV glucose. No significant difference was noted between exercise trials $(P<0.05)$. Data are expressed as mean $\pm \mathrm{SEM}$.
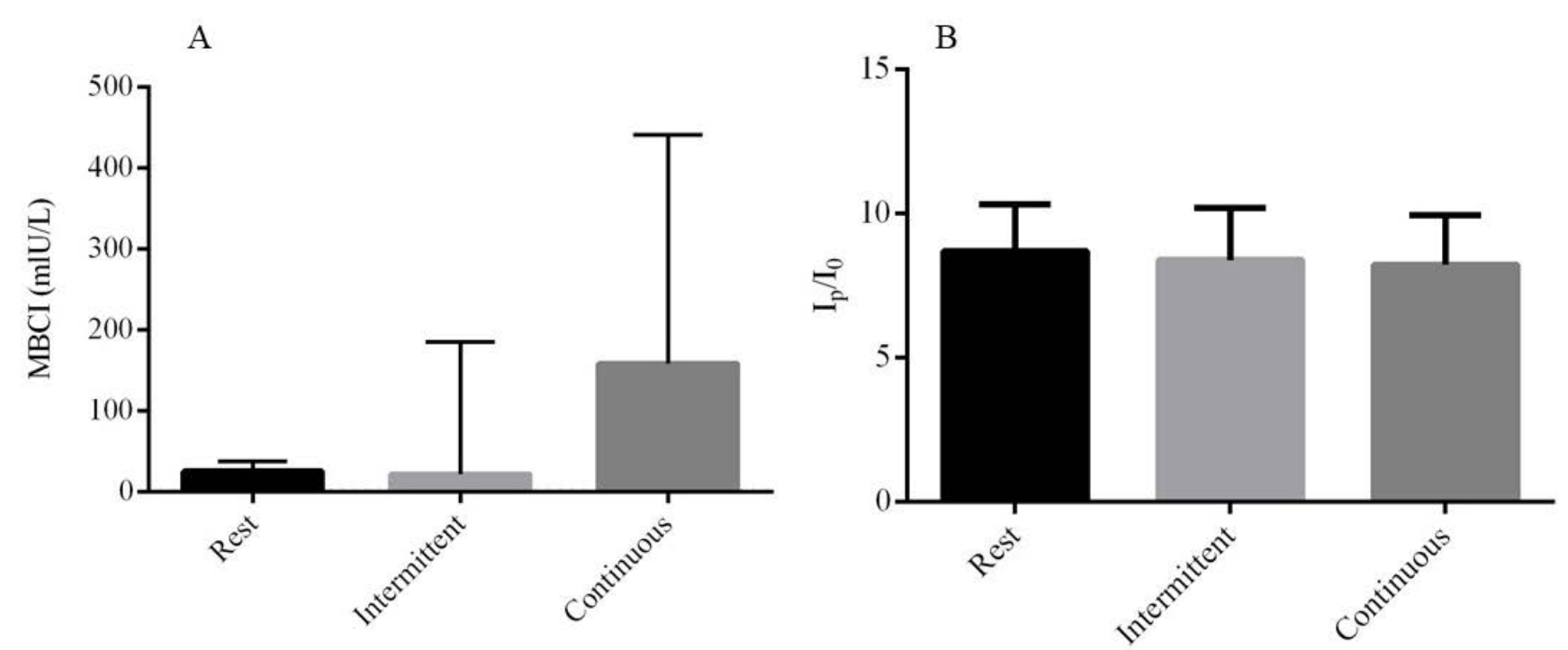

Figure 3: Modified $\beta$-cell function index $(\mathrm{MBCl})(\mathrm{A})$ and the ratio between peak insulin and fasting insulin $\left(\mathrm{I}_{\mathrm{P}} / \mathrm{I}_{0}\right)$ following IV glucose load for rest, intermittent and continuous exercise trials. No significant difference was noted between exercise trials $(P<0.05)$. Data are expressed as mean \pm SEM.

not different between exercise trials and rest. In addition, neither insulin responsiveness, nor $\beta$-cell function was improved by exercise in this hyperinsulinemic pre-diabetic group. This data, combined with our previous findings [11], suggests that acute exercise induced improvements in glycemic control in pre-diabetic individuals is a result of improved peripheral insulin action and skeletal muscle signaling, not $\beta$-cell function. Although this suggestion will need further investigation in a larger cohort of this population.

To optimally regulate whole-body glucose and lipid metabolism, insulin secretion must retain well-characterised qualitative, dynamic characteristics in addition to being quantitatively appropriate [3]. Of these characteristics, the initial secretion of insulin in response to a meal [measured as the $1^{\text {st }}$ phase insulin response to a glucose load $\left.\left(A I R_{g}\right)\right]$ is the most well-studied given that a loss in the $1^{\text {st }}$ phase insulin response leads to a rise in glucose intolerance irrespective of background insulin sensitivity [5]. Our current data showed that exercise did not influence $1^{\text {st }}$ phase or $2^{\text {nd }}$ phase insulin secretion in a pre-diabetic sample. Previous efforts have also shown no change in $1^{\text {st }}$ phase $(0-30 \mathrm{~min})$ or $2^{\text {nd }}$ phase $(30-180$ $\mathrm{min}$ ) insulin response following 6 weeks of high intensity exercise training in type 2 diabetic individuals [35]. However, [35] did show that the same exercise treatment was able to improve DI, in adults with type 2 diabetes, a finding which is not supported by our current or previous research [13]. Thus it can be concluded that insulin resistant, pre-diabetic individuals do not share the capacity for exercise-induced improvements in DI [22]. 
It is, however, important to note that $\beta$-cell function and insulin secretion are highly variable both within and between groups displaying glucose intolerance [36]. Indeed, AIR showed a great deal of variation in our current (pre-diabetics) and previous [28] data sets. Thus, we hypothesised that this variation may be masking clinically relevant data in the treatment of diabetes and that acute exercise may actually improve $\beta$-cell function, yet the methods currently available are not sensitive enough to detect this [36]. The measurement of C-peptide here would have given greater clarity to this hypothesis.

The first-phase insulin response is the initial burst of insulin following an intravenous infusion of glucose, typically measured between time zero (bolus glucose infusion) and 10 $\min$. $\beta$-cell glucose sensitivity, rate sensitivity and the maximal insulin secretory capacity each influence the first-phase insulin response. In normally functioning $\beta$-cells, glucose is rapidly taken up by a pancreatic specific isoform of the glucose transporter family (GLUT-2) and phosphorylated by glucosidase to convert glucose into glucose-6-phosphate (G-6-P) before the formation of pyruvate occurs [2]. Pyruvate then passes into the mitochondria where it is oxidized to produce adenosine triphosphate (ATP). The increased ATP levels result in the closure of $K_{A T P}$ channels, leading to membrane depolarization. The consequence of this is the opening of voltage controlled $\mathrm{Ca}^{2+}$ channels, with an $\mathrm{Ca}^{2+}$ influx and release from the endoplasmic reticulum causing the subsequent release of previously synthesized insulin from secretory vesicles [37]. In the acute post-exercise phase, a reduction in the amount of insulin released is a positive outcome as this demonstrates a reduced insulin requirement owing to improved insulin action. Although marginally lower, the current study showed no difference in AIR between rest and acute exercise regardless of intensity. This was surprising given the hypothesized muscle glycogen depletion with HIIE. In obese and sedentary, although not pre-diabetic individuals $\mathrm{AIR}_{\mathrm{g}}$ was significantly lower following eight months of high intensity exercise training [38], suggesting that exercise training may improve this metabolic parameter.

In summary, since individuals with prediabetes are at increased risk from the progression from pre-diabetes to overt type 2 diabetes, and the prevalence of pre-diabetes is increasing globally [2] it is important to investigate possible interventions that may improve $\beta$-cell function and insulin action. This research indicates that, at least in the acute timeframe, neither high-intensity nor moderate intensity continuous exercise improves $\beta$-cell function or insulin responsiveness. Therefore, given the current data set and our previously published data [11], we conclude that exercise-induced improvements in glycaemic control are attributed to peripheral insulin sensitivity and insulin signalling, and not $\beta$-cell function.

\section{Acknowledgements}

\section{Conflict of interest statement}

There are no conflicts of interests to disclose.

\section{Data availability}

The data used to support the findings of this study are available from corresponding author upon request.

\section{Funding}

This research project did not receive any specific funding, was performed as part of the employment at University of Roehampton.

\section{References}

1. Mackenzie RWA, Watt P (2016) A molecular and whole body insight of the mechanisms surrounding glucose disposal and insulin resistance with hypoxic treatment in skeletal muscle. J Diabetes Res 2016: 1-10.

2. Stumvoll M, Goldstein BJ, Van Haeften TW (2005) Type 2 diabetes: Principles of pathogenesis and therapy. Lancet 365: 13331346.

3. DeFronzo RA, Tripathy D (2009) Skeletal muscle insulin resistance is the primary defect in type 2 diabetes. Diabetes Care 32: S157-S163.

4. George S, Rochford JJ, Wolfrum C, et al. (2004) A family with severe insulin resistance and diabetes due to a mutation in AKT2. Science 304: 1325-1328.

5. Goodpaster BH, Bertoldo A, Ng JM, et al. (2014) Interactions among glucose delivery, transport, and phosphorylation that underlie skeletal muscle insulin resistance in obesity and type 2 diabetes: Studies with dynamic pet imaging. Diabetes 63: 10581068.

6. Karlsson HKR, Zierath JR, Kane S, et al. (2005) Insulin-stimulated phosphorylation of the Akt substrate AS160 is impaired in skeletal muscle of type 2 diabetic subjects. Diabetes 54: 1692-1697.

7. Lillioja S, Mott DM, Spraul M, et al. (1993) Insulin resistance and insulin secretory dysfunction as precursors of non-insulin-dependent diabetes mellitus: Prospective studies of pima indians. N Engl J Med 329: 1988-1992.

8. Plomgaard P, Bouzakri K, Krogh-Madsen R, et al. (2005) Tumor necrosis factor- $\alpha$ induces skeletal muscle insulin resistance in healthy human subjects via inhibition of Akt substrate 160 phosphorylation. Diabetes 54: 2939-2945.

9. Sriwijitkamol A, Coletta DK, Wajcberg E, et al. (2007) Effect of acute exercise on AMPK signaling in skeletal muscle of subjects with type 2 diabetes: A time-course and dose-response study. Diabetes 56: 836-848.

10. Tremblay F, Lavigne $\mathrm{C}$, Jacques $\mathrm{H}$, et al. (2001) Defective insulin-induced glut 4 translocation in skeletal muscle of high fat-fed rats is associated with alterations in both akt/protein kinase $b$ and atypical protein kinase c $(\zeta / \lambda)$ activities. Diabetes 50: 1901-1910.

11. Naufahu J, Elliott B, Markiv A, et al. (2018) High-intensity exercise decreases ip6k1 muscle content and improves insulin sensitivity (s i 2 *) in glucose-intolerant individuals. J Clin Endocrinol Metab 103: 1479-1490.

12. Holloszy JO (2005) Invited review: Exercise-induced increase in muscle insulin sensitivity. J Appl Physiol 99: 338-343.

13. Mackenzie R, Elliott B, Maxwell N, et al. (2012) The effect of hypoxia and work intensity on insulin resistance in type 2 diabetes. J Clin Endocrinol Metab 97: 155-162.

14. Rose AJ, Richter EA (2005) Skeletal muscle glucose uptake during exercise: How is it regulated? Physiology 20: 260-270.

15. Sakamoto K, Holman GD (2008) Emerging role for AS160/TBC1D4 and TBC1D1 in the regulation of GLUT4 traffic. Am J Physiol Endocrinol Metab 295: E29-E37. 
Citation: Ancu O, Naufahu J, Barclay R, et al. (2021) Disposition Index (DI) is not Improved with High-Intensity Intermittent Exercise in Adults with Hyperinsulinemia and Pre-Diabetes. Clin Diabetes Res 5(1):55-61

16. Sjøberg KA, Frøsig C, Kjøbsted R, et al. (2017) Exercise increases human skeletal muscle insulin sensitivity via coordinated increases in microvascular perfusion and molecular signaling. Diabetes 66 : 1501-1510.

17. Harris BA (2005) The influence of endurance and resistance exercise on muscle capillarization in the elderly: A review. Acta Physiol Scand 185: 89-97.

18. Jensen FB (2004) Red blood cell pH, the Bohr effect, and other oxygenation-linked phenomena in blood $\mathrm{O} 2$ and $\mathrm{CO} 2$ transport. Acta Physiol Scand 182: 215-227.

19. Shepherd SO, Cocks M, Tipton KD, et al. (2014) Resistance training increases skeletal muscle oxidative capacity and net intramuscular triglyceride breakdown in type I and II fibres of sedentary males. Exp Physiol 99: 894-908.

20. Cocks M, Shaw CS, Shepherd SO, et al. (2014) Effect of resistance training on microvascular density and enos content in skeletal muscle of sedentary men. Microcirculation 21: 738-746.

21. Bordenave S, Brandou F, Manetta J, et al. (2008) Effects of acute exercise on insulin sensitivity, glucose effectiveness and disposition index in type 2 diabetic patients. Diabetes Metab 34: 250257.

22. Solomon TPJ, Haus JM, Kelly KR, et al. (2010) Improved pancreatic $\beta$-cell function in type 2 diabetic patients after lifestyle-induced weight loss is related to glucose-dependent insulinotropic polypeptide. Diabetes Care 33: 1561-1566.

23. Malin SK, Francois ME, Eichner NZM, et al. (2018) Impact of short-term exercise training intensity on -cell function in older obese adults with prediabetes. J Appl Physiol 125: 1979-1986.

24. Kahn Steven E, McCulloch DKPD (1997) Insulin secretion in the normal and diabetic human. ( $2^{\text {nd }}$ edn), John Wiley \& Sons, New York.

25. Wilcox G (2005) Insulin and insulin resistance. Clin Biochem Rev 26: 19-39.

26. Utzschneider KM, Prigeon RL, Faulenbach MV, et al. (2009) Oral Disposition index predicts the development of future diabetes above and beyond fasting and 2-h glucose levels. Diabetes Care 32: 335-341.
27. Malin SK, Rynders CA, Weltman JY, et al. (2016) Exercise intensity modulates glucose-stimulated insulin secretion when adjusted for adipose, liver and skeletal muscle insulin resistance. PLoS One 11: e0154063.

28. Mackenzie R, Maxwell N, Castle P, et al. (2011) Acute hypoxia and exercise improve insulin sensitivity ( $\left.\mathrm{SI} 2^{*}\right)$ in individuals with type 2 diabetes. Diabetes Metab Res Rev 27: 94-101.

29. American Diabetes Association (2014) Diagnosis and classification of diabetes mellitus. Diabetes Care 37: S81-90.

30. Kosicka A, Cunliffe AD, Mackenzie R, et al. (2013) Attenuation of plasma annexin A1 in human obesity. FASEB J 27: 368-378.

31. Vicini P, Caumo A, Cobelli C (1997) The hot IVGTT two-compartment minimal model: Indexes of glucose effectiveness and insulin sensitivity. Am J Physiol 273: 1024-1032.

32. Bravata DM, Sanders L, Huang J, et al. (2003) Efficacy and safety of low-carbohydrate diets: A systematic review. JAMA 289: 1837-1850.

33. Li J, Kuang Y, Mason CC (2006) Modeling the glucose-insulin regulatory system and ultradian insulin secretory oscillations with two explicit time delays. J Theor Biol 242: 722-735.

34. Madsen SM, Thorup AC, Overgaard K, et al. (2015) High intensity interval training improves glycaemic control and pancreatic $\beta$ cell function of type 2 diabetes patients. PLoS One 10: e0133286.

35. Nieuwoudt S, Fealy CE, Foucher JA, et al. (2017) Functional high-intensity training improves pancreatic $\beta$-cell function in adults with type 2 diabetes. Am J Physiol Endocrinol Metab 313: E314-E320.

36. Vague $P$, Nguyen $L$ (2001) Rationale and methods for the estimation of insulin secretion in a given patient: From research to clinical practice. Diabetes 51: S240-S244.

37. Gabbay KH, Korff J, Schneeberger EE (1975) Vesicular binesis: Glucose effect on insulin secretory vesicles. Science 187: 177179.

38. Slentz CA, Tanner CJ, Bateman LA, et al. (2009) Effects of exercise training intensity on pancreatic $\beta$-cell function. Diabetes Care 32: 1807-1811. 
Citation: Ancu O, Naufahu J, Barclay R, et al. (2021) Disposition Index (DI) is not Improved with High-Intensity Intermittent Exercise in Adults with Hyperinsulinemia and Pre-Diabetes. Clin Diabetes Res 5(1):55-61

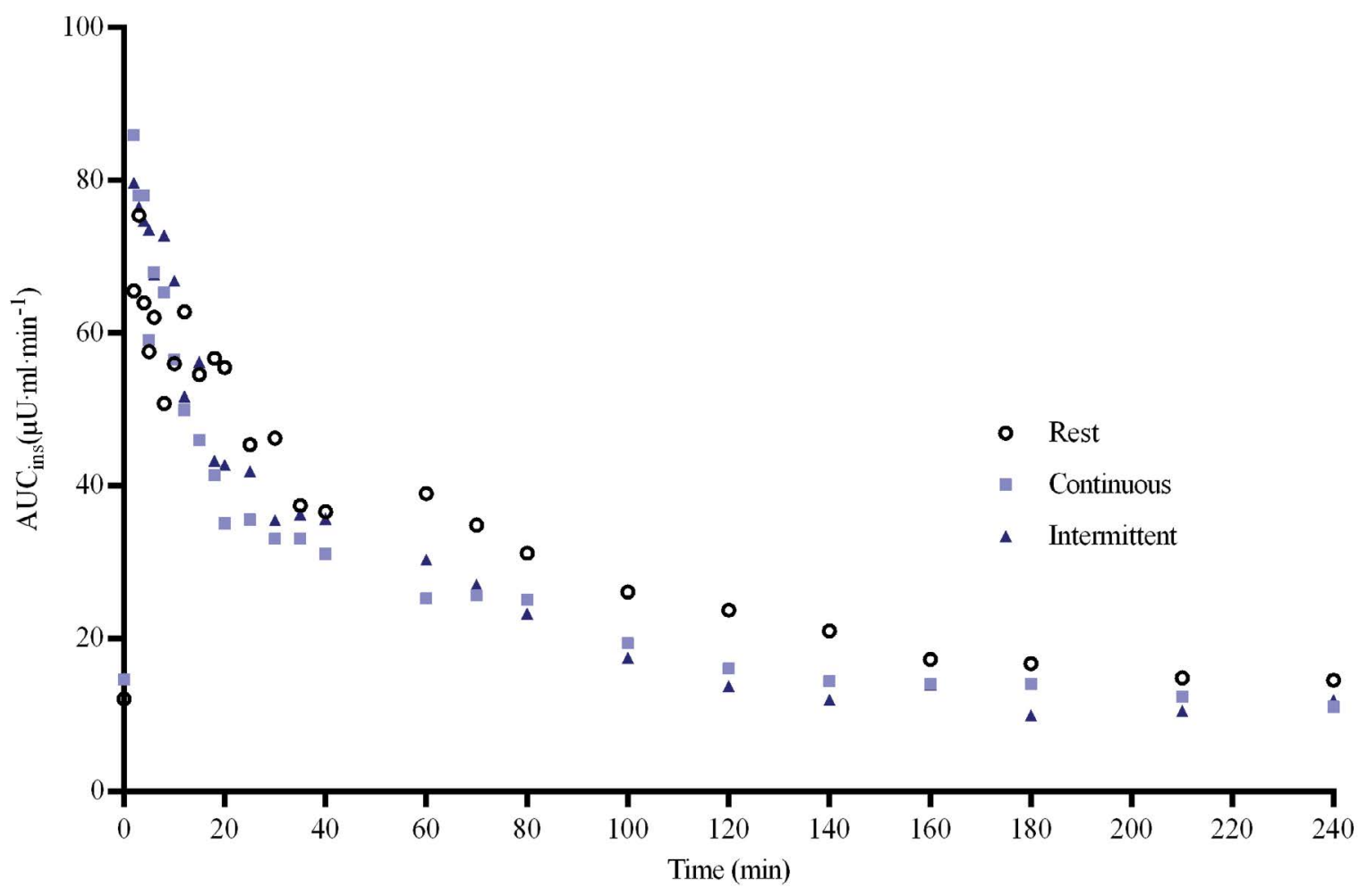

Figure 1: Shows plasma insulin concentrations against timepoints and area under the curve for insulin (AUC ${ }_{\text {Ins }}$ ) during the intravenous glucose tolerance test post rest, intermittent and continuous exercise trials.

Table 1: Subjects' clinical, physiological and metabolic characteristics.

\begin{tabular}{|l|l|l|l|l|l|l|l|}
\hline Age (yr) & BMI (kg/m²) & Body Fat (\%) & HbA $_{\mathbf{1 c}}$ (\%) & $\begin{array}{l}\text { Fasting Glucose } \\
\text { (mmol/L) }\end{array}$ & $\begin{array}{l}\text { Fasting Glucose } \\
\text { (mmol/L) }\end{array}$ & HOMA $_{\text {-cell }}$ & $\begin{array}{l}\text { Fasting insulin } \\
\text { (mmol/L) }\end{array}$ \\
\hline $47(3)$ & $32.0(2.4)$ & $39.0(4.4)$ & $6.1(0.2)$ & $5.3(0.7)$ & $3.3(0.8)$ & $207(33)$ & $11.6(5.9)$ \\
\hline
\end{tabular}

Values are means (SEM). Body Mass Index (BMI); Glycosylated Haemoglobin (HbA1c), Homeostasis Model Assessment of Insulin Resistance $\left(\mathrm{HOMA}_{\mathrm{IR}}\right) ;$; -Cell function $\left(\mathrm{HOMA}_{\beta \text {-cell }}\right)$.

DOI: $10.36959 / 647 / 495$

Copyright: (C) 2021 Ancu O, et al. This is an open-access article distributed under the terms of the Creative Commons Attribution License, which permits unrestricted use, distribution, and reproduction in any medium, provided the original author and source are credited. 